\section{Intern ationa l}

Journal of

Medical

and Surgical

\section{Sciences}

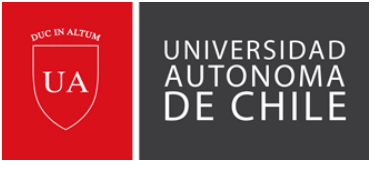

\title{
Characterization of the intensive care unit (ICU) admissions in the Benue State University Teaching Hospital.
}

\author{
Michael Enokela Efu, ${ }^{1}$ Babarinde 0jo, ${ }^{2}$ Barnabas Agaba Eke, ${ }^{3}$ Gabriel Okpotu Anefu ${ }^{4}$ \\ \& Martha Amaka Ozoagu. ${ }^{5}$
}

\section{ABSTRACT}

Today, intensive care units (ICUs) of most hospitals in developed countries have become separate departments staffed by career intensive care physicians or intensivists from various fields of medicine. In Nigeria, however, ICUs are still part of the anaesthesia department and critical care constitutes a significant part of the workload and responsibilities of anesthetists. This study was carried out to ascertain the types of disease conditions that were brought into the ICU for management at the Benue State University Teaching Hospital (BSUTH), interventions undertaken as well as the outcome of such admissions. A total of 125 patients were evaluated. The age bracket between 21 and 30 years recorded the highest figure of 28 accounting for $22.4 \%$ of the study population. This was followed by the age bracket between 31 and 40 years with 24 representing $19.2 \%$. The study population was made up of 81 males and 44 females making up $64.8 \%$ and $35.2 \%$, respectively. The most frequent conditions occasioning ICU admissions are post laparotomy (24.8\%), head injury (18.4\%), and burns (11.2\%). A total of 289 interventions in various combinations were carried out on these patients. Of these, monitoring of the patients was undertaken 106 times, representing 36.7\%. Oxygen therapy followed closely with 102 (35.3\%). The lowest number of days spent by patients in the ICU in this study, was 1, while the longest was 35 with a mean of 5.97 days \pm 7.76 days. Majority of the patients, 68 , were discharged from the ICU to the wards making up $54.4 \%$ of the study population. This was closely followed by those that died, 50 , accounting for $40.0 \%$ of the study population. This study has established that in our ICU, the most common indications for admission were post-laparotomy, head injury and burns. Also, it has been observed that most of the patients underwent haemodynamic monitoring and oxygen therapy. Finally, while most patients admitted were discharged to the wards, a good number also died in the ICU.

Keywords: ICU, Nigeria, injury, burns.

\section{INTRODUCTION}

Intensive care has been defined as "a service for patients with potentially recoverable conditions who can benefit from more detailed observation and invasive treatment than can safely be provided in general wards or high dependency areas". It is usually reserved for patients with potential or established organ failure (Smith \& Nielsen, 1999). Intensive care is suitable for patients requiring or likely to require advanced respiratory support, patients requiring support of two or more organ systems, and patients with long-lasting deficiency of one or more organ systems, who also require support for an acute reversible failure of another organ. Early referral is particularly important. If referral is delayed until the patient's life is clearly at risk, the chances of full recovery are jeopardized (Smith \& Nielsen, 1999). In 1950, anesthesiologist Peter Safar established the concept of "advanced life support", keeping patients sedated and ventilated in an intensive care environment. Safar is considered to be the first practitioner of intensive care medicine as a specialty.

In response to a polio epidemic (where many patients required constant ventilation and surveillance), Bjørn Aage Ibsen established the first intensive care unit in 
Copenhagen in 1953 (Reisner-Sénélar, 2009; Reisner-Sénélar, 2009).

The first application of this idea in the United States was in 1955 by William Mosenthal, a surgeon at the Dartmouth-Hitchcock Medical Center (Grossman, 2004). In the 1960s, the importance of cardiac arrhythmias as a source of morbidity and mortality in myocardial infarctions (heart attacks) was recognized. This led to the routine use of cardiac monitoring in ICUs, especially after heart attacks (Brazilian Society of Critical Care, 2008). By the 1960's many institutions had developed "respiratory care units" to facilitate the management of patients requiring mechanical ventilation. At the same time, coronary care units were also established for the intensive postoperative care of patients who had undergone cardiac surgery while surgical units managed patients who had undergone major surgical procedures (Bjorneboe, 1955).

Today, intensive care units (ICUs) of most hospitals in developed countries have become separate departments staffed by career intensive care physicians or intensivists from various fields of medicine (Oh, 1992). In Nigeria, however, ICUs are still part of the anaesthesia department and critical care constitutes a substantial part of the workload and responsibilities of anaesthetists (Oyegunle \& Oyegunle, 1997). As with any other treatment, the decision to admit a patient to an intensive care unit should be based on the concept of likely benefit. Patients who are too well to benefit or those with no hope of recovering to an adequate quality of life should not be admitted (Smith \& Nielsen, 1999).

This study was carried out to ascertain the types of disease conditions that were brought into the ICU for management at the Benue State University Teaching Hospital (BSUTH), interventions undertaken, as well as the outcome of such admissions.

\section{METHODOLOGY}

This was a three-year retrospective study carried out in BSUTH, Makurdi, a 360 bed hospital situated in the capital city of Benue State, North Central Nigeria. All patients admitted into the ICU of the BSUTH between January 2016 and December 2018 were evaluated. All patients admitted in all of the other wards outside the ICU were excluded.

A total of 125 case files of eligible patients were retrieved from the records department of BSUTH after an application to the department was approved. Relevant information was extracted from the patients' folders and transferred into a prepared proforma. The data collected included age, sex, diagnosis, types of intervention in ICU, number of days the patient spent in ICU and the outcome of such ICU admission. The data so collected were analyzed using SPSS version 25, using simple statistics.

The approval of the BSUTH Research and Ethical Committee was sought and obtained.

\section{RESULTS}

A total of 125 patients were evaluated. The age bracket between 21 and 30 years recorded the highest figure of 28 accounting for $22.4 \%$ of the study population. This was followed by the age bracket between 31 and 40 years with 24, representing $19.2 \%$. Figures obtained for age brackets 0 to 10 years, 11 to 20 years, 41 to 50 years, 51 to 60 years, 61 to 70 years, 71 to 80 years and 81 to 90 years were $16(12.8 \%), 19$ (15.2\%), 15 (12.0\%), 10 (8.0\%), 9 (7.2\%), 3 (2.4\%) and 1 (0.8\%), respectively. The study population was made up of 81 males and 44 females making up $64.8 \%$ and $35.2 \%$, respectively.

The most frequent conditions occasioning ICU admissions are post laparotomy (24.8\%), head injury (18.4\%), and burns injury (11.2\%). Hypovolaemic shock occurred 5 times representing $4.0 \%$, while post thyroidectomy and septicaemia were observed 4 times each, accounting for 3.2\% each also. Both cerebro-vascular disease (CVD) and post tracheostomy were observed 3 times each accounting for $2.4 \%$ each of the study population. Conditions necessitating ICU admission that were observed twice each making up $1.6 \%$ each also of the study population were post cardiac arrest on the table, post thoracotomy, poly-traumatized, intra-operative Eclampsia, post-partum Eclampsia and status epilepticus. Many other conditions occurred once each totaling 26 and they make up $20.8 \%$ of the study population.

A total of 289 interventions in various combinations were carried out on these patients. Of these, monitoring of the patients was undertaken 106 times, representing 36.7\%. Oxygen therapy followed closely with 102 (35.3\%). Cardiopulmonary resuscitation with $35(12.1 \%)$, endotracheal intubation with 34 (11.8\%), mechanical ventilation with $7(2.4 \%)$, tracheostomy tube suctioning with 3 (1.0) and awake extubation with 2 (0.7\%) accounted for the rest of the interventions carried out.

The lowest number of days spent by patients in the ICU in this study, was 1 , while the longest was 35 with a mean of 5.97 days \pm 7.76 days.

Majority of the patients, 68, were discharged from the ICU to the wards making up $54.4 \%$ of the study population. This was closely followed by those that died, 50 , accounting for $40.0 \%$ of the study population. While $6(4.8 \%)$ patients were transferred to other hospitals, $1(0.8 \%)$ was discharged against medical advice.

\section{DISCUSSION}

A summation of the ages between 0 and 50 years make up $81.6 \%$ of the study population. This demonstrates that an overwhelming majority of the patients admitted into the ICU are young people. Young people naturally indulge in ventures that 
could result in certain morbidities that could warrant ICU admission. This result is comparable with results obtained by Poluyi et al. (2016) in Lagos University Teaching Hospital (LUTH), Lagos, as well as that also obtained by Isamade et al. (2007) in Jos University Teaching Hospital (JUTH), Jos.

From the results obtained, the three most common indications for ICU admission were post laparotomy, head injury and burns injury. It is conditions such as head injury, mostly from road traffic accidents, and burns injury that tilt the study population in favour of both the male gender and the youth in the demographic characteristics demonstrated above. In the study by Poluyi et al. (2016) neurosurgery was observed to be the highest surgical specialty utilizing the ICU bed spaces. This was different from the study done by Mato et al. (2009) where the Obstetrics department was the highest specialty utilizing the ICU bed space. This could be attributed to the availability of neurosurgical specialty care that the former centre provided (Poluyi et al., 2016). The study by Poluyi et al. (2016) also demonstrated that Severe Traumatic brain injury (TBI) accounted for $77.3 \%$ (160) of all Neurosurgical admissions, which equally agrees with a study done in Britain where high velocity injuries were caused by rapid acceleration and deceleration (Helmy et al., 2007). In their own study, Adenekan and Faponle (2009) observed that road traffic crashes were responsible for most deaths and major trauma admissions to the ICU.

The mean number of days spent in the ICU was around six. This is probably because the majority of the indications were post-surgical cases that were discharged to the wards as soon as they were able to recover sufficiently. Also, the more critically ill died in the ICU a few days after admission accounting for the mean short duration of stay.

Numerous interventions were carried out on the patients on admission into the ICU. Being a small unit with few trained personnel, most of the interventions carried out were routine non-invasive techniques, such as haemodynamic monitoring and oxygen therapy, jointly making up $72 \%$ of all intervention techniques. Also, while cardio pulmonary resuscitation (CPR) accounted for $12.1 \%$ of all intervention procedures, invasive techniques such as endotracheal intubation and mechanical ventilation were responsible for $11.8 \%$ and $2.4 \%$ of the techniques, respectively.

While most of the patients were transferred from the ICU to the wards, $40 \%$ of the study population died. This mortality rate is lower than that obtained by Poluyi et al. (2016). On the other hand, the result is slightly higher than the national average of between 30 to $37.6 \%$. Also, 4.8\% were transferred to other facilities and $0.8 \%$ was discharged against medical advice. Patients who were referred either went to centers higher than ours or to centers of patients' preferences for reasons such as proximity to their homes, etc. In our environment, ignorance still makes people to take away their patients against medical advice.

\section{CONCLUSION}

This study has demonstrated that in our ICU the most common indications for admission were post-laparotomy, head injury and burns injury. Also, it has been observed that most of the patients underwent haemodynamic monitoring and oxygen therapy. Finally, while most patients admitted were discharged to the wards, a good number also died in the ICU.

\section{REFERENCES}

Adenekan AT, Faponle AF. Trauma admissions to the ICU of a tertiary hospital in a low resource setting. Afr J Anaesth Intensive Care 2009;9: 5-9.

Bjorneboe M, Ibsen B, Astrup P, Everberg G, Harvald B, Sottrup T, Thaysen $\mathrm{EH}$, Thorshauge $\mathrm{C}$. Active ventilation in treatment of respiratory acidosis in chronic disease of the lungs. Lancet 1955; 269(6896): 901-903.

Brazilian Society of Critical Care. [Internet]. "História da Terapia Intensiva" [Intensive Care History] (video in English linked to from website). Brazilian Society of Critical Care website. Available at: https://www.youtube.com/wat$c h ? v=C F 210$ wlrS_M\&gl=BR.

Grossman DC. "Vital Signs: Remembering Dr. William Mosenthal: A simple idea from a special surgeon”. Dartmouth Medicine 2004; 28(3).

Helmy A, Vizcaychipi M, Gupta AK. Traumatic brain injury: Intensive care management. Br J Anaesth. 2007;99(1): 32-42.

Isamade ES, Yiltok SJ, Uba AF, Isamade El, Daru PH. Intensive care unit admissions in the Jos University Teaching Hospital. Niger J Clin Pract. 2007; 10(2): 156-161.

Mato CN, Onwuchekwa AC, Aggo AT. Pattern of admission to the University of Portharcourt Teaching Hospital (UPTH) Intensive Care Unit-A 10 year analysis. South Am J Crit Care 2009;25: 10.

Oh TE. Intensive care in Hong Kong where now? J Hongkong Med Ass Association 1992;44: 57.

Oyegunle A0, Oyegunle VA. The intensive care unit in a young Nigerian Teaching Hospital. The sagamu (1994-1997) experience. A restropective study. Afr J Anaesth Intensive Care 1997;3: 41-43.

Poluyi EO, Fadiran 00, Poluyi CO, Alabi EO, Falohun SA. Profile of Intensive Care Unit Admissions and Outcomes in a Tertiary Care Center of a Developing Country in West Africa: A 5 Year Analysis. J Intensive Crit Care 2016; 2:3.

Reisner-Sénélar L. “Der dänische Anästhesist Björn Ibsen ein Pionier der Langzeitbeatmung über die oberen Luftwege”. [Doctoral Thesis] (in German). Frankfurt am Main, Germany: Johann Wolfgang Goethe University; 2009.

Reisner-Sénélar L. "The Danish anaesthesiologist was a pioneer of long-term ventilation on the upper airways". 2009. (PDF). [dead link].

Smith G, Nielsen M. Criteria for admission. BMJ. 1999;318(7197): 1544-1547. 